\title{
ALTERNATIVE STAINING OF FASCIOLA GIGANTICA USING NATURAL HERBAL DYES \\ By
}

MARWA E. ALY ${ }^{1}$, AHMED K. DYAB ${ }^{2}$, DOAA A. YONES ${ }^{2}$, YASSER M. MOHAMED ${ }^{2}$, SOAAD A. BAYOUMI ${ }^{3}$ AND NAHED A. ELOSSILY ${ }^{2}$ Animal Health Research Institute ${ }^{1}$, and Department of Medical Parasitology ${ }^{2}$, Faculty of Medicine, Assuit University, and Department of Pharmacognosy ${ }^{3}$, Faculty of Pharmacy, Assuit University, Egypt

( ${ }^{*}$ Correspondence: ahmedsaf2001@yahoo.com)

\section{Abstract}

The Aqueous extracts of red beet, China rose, henna and acid carmine stains were used to stain the adult worms of $F$. gigantca. The stained flukes showed varying degrees of pigmentation with well-defined external and internal structure. Oral and ventral sucker, muscular pharynx, oesophagus, intestinal ceca and cirrus sac took rose to light cherry color in aqueous extract of china rose, orange to brown color in aqueous extract of sugar beet, beige to pale brown color in aqueous extract of henna while they took deep red color in carmine stain with best quality achieved by china rose aqueous extract. The ovary, testes and longitudinal excretory canal/pore took rose to cherry color in aqueous extract of China rose, pale brown color in aqueous extracts of both sugar beet and henna while they acquired red to pink color in acid carmine stain. Aqueous extracts of sugar beet exhibited little better quality in revealing characteristics of vitelline ducts and vitelline glands compared to the aqueous extract of China rose, henna and carmine stain. Uterus stained brown in both sugar beet aqueous extracts and carmine stain while it took yellow color when stained with China rose and henna. Eggs inside uterus took light yellow color in all tested aqueous extracts. Ootype/mehli's gland and yolk reservoir of $F$. gigantica took brown color in aqueous extracts of red beet, China rose and henna, red to pink color in carmine stain. Spines covering the cuticle appeared rose color in aqueous extract of china rose, pale brown color in aqueous extract of sugar beet extract and henna, and pale red color in carmine stain.

Key words: Fasciola gigantica, Natural herbal dyes

\section{Introduction}

In parasitological laboratory, direct wet mount is primarily used in order to detect parasites. But the more accurate identification of parasite, especially in taxonomic studies of trematode, cestode, nematode, and also for the differentiation of parasitic egg and larva is still based on detection of specific morphological features and details of internal structures after staining them using synthetic dyes, hematoxylin, carmine, acetocarmine, eosin, Romanowsky stain, Lactophenol cotton blue, Lugol's iodine, malachite green...etc. (Zeibig, 2013). However, these conventional dyes are imported and expensive and some of them can impose some adverse effects on human health including an irritation, allergic reaction and burning sensation to eye, skin, nose and throat besides some are carcinogenic in nature. Thus, the use of herbal dyes as an effective, ecofriendly and biodegradable alternative meth- ods was favored. The majority of the natural dyes are extracts from plant sources as roots, bark, leaves, wood and other organic sources like fungi and insects (Afshar, 2002; Ratna and Padhi, 2012; Suebkhampet and Naimon, 2014).

Until the late $19^{\text {th }}$ Century, natural dyes extracted from plants, animals and minerals were used as primary staining material in the textile, paint, and other industries (Afshar, 2002). But, with the development of cheaper, brighter, more convenient and feasible synthetic dyes, the use of natural dyes have decreased (Bhuyan and Saikia, 2005).

The scientists become aware of ecological and environmental problems related to the synthetic dyes the use of natural dyes has gained interest once more (Eom et al, 2001). Although methods of preparation of herbal dyes are more complex than the commercial dyes but their staining quality and stability are much better than the synthetic dyes (Rat- 
na and Padhi, 2012). Vibrant colors can be produced from natural dyes by mixing them with each other in different proportion. Besides, these natural dyes could consequently provide a new economy source to the country (Al-Almura et al, 2012). A number of aqueous and alcoholic extracts of natural dyes such as henna, alizarin (Daryani et al, 2011), China rose, sugar beet and red rose (Rosa bybrida) (Kumar et al, 2015) were evaluated for Platyhelminthes staining. Also, extracts of $H$. rosainensis and Beta vulgaris were employed to detect some intestinal nematodes eggs (Cheng et al, 2014).

Sugar or red beet (Beta vulgaris) is used in medicine, various ailments and importantly as a natural colorant in ice cream, beverages, and some fruit products (Roy et al, 2004). The China rose, Hibiscus rosasinensis has colorful flowers ranging from white through yellows and reds (Ku-mar and Singh, 2002). It has a number of medicinal uses, as it contains flavonoid, polyphenols and anthocyanins. It may have some potential in cosmetic skin care as an anti-solar agent by absorbing ultraviolet radiation (Sidram et al, 2011). It is also used as a colorant to various edible and in-edible items (Attokaran, 2012). They have been also used for commercial perfumery and commercial cut flower crops. They are made into jelly, marmalade, syrup, jam and soup or brewed for tea, primarily for their high Vitamin $\mathrm{C}$ content. It can be used in skin products and some makeup products. Rose water due to its distinctive flavor is used in sweets. They have minor medicinal uses (Saati et al, 2011). Of late, attempts were made to use henna (Lawsonia inermis) as a biologic stain for plants and microorganisms (Chukwu et al, 2011). Staining property of henna is mainly attributed to a naphthoquinone compound named as lawsone that is abundance in the dried leaves imparting a brown color because they have chemical properties analogous to tannic acid and thus name hennotannic acid (Semwal et al, 2014).

The present study aimed at evaluating the quality of aqueous extracts of sugar beet (Beta vulgaris), China rose (Hibiscus rosa sinensis) and henna as an alternative stain to chemical, synthetic, conventional dye (acid carmine) in staining of $F$. gigantica in parasitology laboratory.

\section{Material and Methods}

The study was carried out in the research laboratory, Department of Parasitology, Faculty of Medicine, Assiut University.

Flowers China rose and the roots of red beet were purchased from the local market. Henna plant kindly brought from Faculty of Pharmacy, Assiut University.

Sample collection and fixation: Fasciola gigantica adults were collected from naturally infected liver of cattle slaughtered in different slaughter houses in Assiut and Sohag Governorates (Ghavami et al, 2009). The flukes were washed many times using distilled water, gently flattened and tied between two glass slides and preserved in 10\% neutral formalin until use (Muller, 2002).

Preparation of aqueous extracts of herbal dyes: Dried red beet roots, flowers of hibiscus and dried leaves of henna were ground into powder by electric grinder, Based on a previous experimental survey on many natural herbal dyes (Daryani and Meigouni, 2010; Marhaba and Haniloo, 2018), 5, 10 \& 20 grams of each prepared herbal powder were dissolved in $100 \mathrm{ml}$ distilled water separately to make the concentrations of 0.05 , $0.1 \& 0.2 \mathrm{~g} / \mathrm{ml}(5 \%, 10 \% \& 20 \%$; w/v) respectively. The solutions were heated for $3 \mathrm{hr}$ at $70^{\circ} \mathrm{C}$ in a water bath. After cooling, extracts were undergone purification procedure by a double filtration process, primary filtrated by passing the extract through a filter wire mesh, next the filtrate was purified using Whatman filter paper. Lastly, the filtrates were centrifuged at $3000 \mathrm{rpm}$ for $15 \mathrm{~min}$., the supernatant was transferred into dark bottles labeled accordingly until the experimental time.

Staining of $F$. gigantica adults: The fixed $F$. gigantica samples were stained separately with different concentrations of herbal extr- 
acts $(5 \%, 10 \% \& 20 \% ; \mathrm{w} / \mathrm{v})$ and carmine dyes (as control) according to carmine staining method (Muller, 2002) as follows: fixed samples were washed with tap water twice and immersed in plates containing the dye solutions (2-6hr) then washed with tap water again. Samples were moved into acid alcohol $(2 \mathrm{ml}$ of concentrated HCL in $100 \mathrm{ml}$ of $70 \%$ ethanol) for $20 \mathrm{sec}$ to $2 \mathrm{~min}$, to eliminate the excessive stain without loss of pigmentation. Samples were subsequently dehydrated in $50 \%, 70 \%, 85 \%, 96 \%$ \& $100 \%$ ethanol (each step took $15 \mathrm{~min}$ ), ethanol-xylene (30min) and xylene (30min). Then, they were mounted using Canada balsam. Structural brightness and extent of staining on different parts of samples such as tegument, suckers, intestine and reproductive systems (tests, ootype, vitelline duct, vitellaria, ovary, uterus \& eggs) of $F$. gigantica adults were examined by light microscopy. Acetic acid alum carmine stain was used as a control. Permanently mounted samples monitored microscopically each three months for one year to detect any possible apparent decrease in quality of staining. However, it was not quantitatively analyzed.

Ethical approval: Not indicated, as the study was done using plant extracts and parasites were collected during post-mortem examination.

\section{Results}

Extracts staining solutions: Extracts of red beet, China rose and henna showed slight acidity, when examined using $\mathrm{pH}$ meter. Red beet extracts appeared dark red to brown in color while aqueous extracts of the rose appeared pink to pink-red in color and extracts of henna appeared pink in color. The optimum concentrations of different extracts for flukes staining were $(10 \%$; w $/ \mathrm{v})$. These extracts retained their dying ability and stability for about one year when stored at $4{ }^{\circ} \mathrm{C}$. Stained flukes acquired a varying degree of pigmentation with the distinction of their internal structure using the three herbal extracts which were compared to carmine stained as control samples. Color of extracts was absorbed by the parasite tissues. Types of extracts did not impart a too much significant difference in coloring pattern of stained specimens (Fig. 1).

By microscopy $F$. gigantica samples were evidently stained by aqueous extract of red beet, china rose, henna and carmine stain "as a control" and shown well-defined external and internal structure, whence the following point well be giving more details: Oral and ventral sucker, muscular pharynx, oesophagus, two intestinal ceca and cirrus sac took rose to light cherry color with good contrast in aqueous extract of china rose, orange to brown color in aqueous extract of sugar beet, beige to pale brown color in aqueous extract of henna while they took deep red color in carmine stain (Figs. 2, 3). Ovary and testes took rose to cherry color in aqueous extract of China rose, pale brown color in aqueous extracts of both sugar beet and henna while they acquired red to pink color in carmine stain. Aqueous extract of sugar beet and henna were more efficient than aqueous extract of China rose and carmine stain in staining of $F$. gigantica's ovary (Figs 4,5 ).

Longitudinal excretory canal/pore took light brown color in aqueous extract of sugar beet and henna, rose to cherry color in aqueous extract of China rose and red color in carmine stain (Fig. 6). Vitellinaria and vitelline ducts took the light brown color in aqueous extract of China rose, sugar beet and henna while it acquired deep pink color in carmine stain. Aqueous extracts of sugar beet exhibited little better quality in revealing characteristics of vitelline ducts and vitelline glands compared to the aqueous extract of China rose, henna and carmine stain (Fig. 7). Uterus stained brown in both sugar beet aqueous extracts and carmine stain, but it took yellow color when stained with China rose and henna. Eggs were ovoid, thin shelled, operculated and took light yellow color in all tested aqueous extracts (Fig. 8). Ootype/mehli's gland and yolk reservoir of $F$. gigantica took brown color in aqueous extracts of red beet, China rose and henna, red 
to pink color in carmine stain and beige to light brown color in aqueous extract of henna (Fig. 7). Spines covering cuticle appeared rose color in aqueous extract of china rose, pale brown color in aqueous extract of sugar beet extract and henna, and pale red color in carmine stain (Fig. 8).

Staining characteristics of uterus, egg, Ootype, Mehli's gland and spines obtained by using aqueous extracts and carmine stain were almost the same in quality. Aqueous extract of China rose showed higher scores and better quality compared to sugar beet, henna and carmine stain in staining organs of $F$. gigantica oral/ ventral sucker, cirrus sac and intestinal ceca's branches as it imparted the more contrasting color.

\section{Discussion}

Many authors were evaluated the competence of natural dyes to stain different parasites as an alternative to conventional staining procedures to determine the taxonomic position and for identification purpose $(\mathrm{Ku}-$ mar et al, 2015).

In the present study, red beet, China rose and henna aqueous extracts were used for staining $F$. gigantica adults. Aqueous extracts with $10 \%(\mathrm{w} / \mathrm{v})$ concentrations of red beet, China rose and henna were able to stain different internal and external structures of $F$. gigantica adults with varying degrees of pigmentation. Differential staining of the worm structures resulted from the variance in their composition as the body and tegment of trematodes composed of muscle fibers, layers of glycocalyx and other substances (Roberts and Janovy, 2005).

The $\mathrm{pH}$ of the aqueous extracts determined the ability of a dye to stain specific tissue structures (Avwioro, 2002). Charge dis tribution of dye determined attractive or repulsive characteristics of the dye. Cations $(+)$ /positive and anions $(-) /$ negative charges were attracted to the positively \& negatively charged molecules, respectively. So, charge was largely determined by $\mathrm{pH}$ of the dye extracts. High $\mathrm{pH}$ solution decreased number of charged groups within the tissue. So, $\mathrm{pH}$ of the extracts could be a reason explaining why these extracts were able to stain Platyhelminthes differential. Affinity was the results of attractive forces between dye and tissue molecules. Dyes have a greater affinity for tissue molecules than solvent molecules (Kumar et al, 2015). Affinity of dyes for tissue elements was affected by many factors: structure, shape and charge distribution of the dye molecule and solvent characteristics (Avwioro, 2011).

In the present study, the extracts maintained their dying ability and stability for about one year when stored at $4{ }^{\circ} \mathrm{C}$. Also, all the extracts retained color in permanent mounted examined helminthes for more than 6 months, as the permanent mounted samples monitored microscopically each three months until one year for any possible apparent decrease in quality of staining. This agreed with previous study stated that stained specimens using herbal extract pigments were kept without decay for more than one year (Al Amural et al, 2012) and for more than 6 months (Kumar et al, 2015).

In this study, aqueous extract of China rose showed better quality in staining of various organs and parts of F. gigantic compared to the aqueous extracts of sugar beet, henna and carmine stain. Oral sucker, muscular pharynx, esophagus, intestinal caeca, ventral sucker and cirrus sac took rose to light cherry color with good contrast in using aqueous extract to china rose, orange to brown color in aqueous extract of sugar beet, while they took beige to pale brown color in aqueous extract of henna compared to deep red color produced by carmine stain. The reason for these differential pigmentation could be explained as the sugar beet extract imparted yellow to brown color to the parasites specimens because they are enriched in many pigment component like betacyanin (red color) and betanin, isobetanin and betanidin (yellow color) (Boris et al, 2011). But, roses imparted pink to pink-red color was due to the flavonoids pigments, including most prevalent water-soluble anth- 
ocyanin pigment (Yoshikazu et al, 2009).

Aqueous extract of sugar beet and henna were more efficient than aqueous extract of China rose and carmine stain in staining $F$. gigantica's ovary. However, aqueous extract of henna possessed a little higher quality in the staining of testes. Ovary and testes took rose to cherry color in aqueous extract of China rose, pale brown color in aqueous extract of sugar beet and henna, red to pink color in carmine stain. These results agreed with Daryani and Meigouni (2010) they found better quality of henna in staining Fasciola when compared to curcuma.

In the present study, the aqueous extracts and carmine stain gave almost the same staining characteristics in different $F$. gigantica organs (vitelline glands and ducts, uterus, ootype and mehlis' gland. A little better quality detected with the use of sugar beet aqueous extract pigmentation where the vitelline ducts branching was more detailed. vitelline glands and ducts, uterus, ootype, mehlis gland as well as yolk reservoir took color ranging from beige to dark brown on using the three tested aqueous extracts, but these organs acquired pale to dark rose in carmine stain. However, F. gigantica eggs inside the uterus appeared light yellow in all herbal extracts as well as carmine stain. The results agreed with Kumar et al, (2015) in which, red beet, China rose and red rose were used as an alternative stain to conventional dye, hematoxylin in staining of a flatworms ( $F$. gigantica and Gastrothylax crumenifer). They reported that liver and rumen fluke's internal structure, oral and ventral sucker, cirrus sac, testes, ovary, vitallaria and uterus with eggs were appeared light to deep pink color in aqueous and alcoholic extract of China and red rose while yellow to brown color in sugar beet extract. The rose's extracts were better than sugar beet extract in staining the worm, $F$. gigantica and $G$. crumenifer, especially sucker, branched intestine, vitelline duct, vitelline gland, ootype, and body spines. Red rose aqueous extract was a suitable dye and clearly de- fined internal organ of parasites; egg, body surface spines and especially branched tests of trematodes as compared to China rose extract (Kumar et al, 2015).

The staining characteristics of $F$. gigantica spines were almost similar in the tested three aqueous extracts as well as in carmine stain where the spines appeared rose or pale red in both China rose aqueous extract and carmine stain, while they took pale brown color in aqueous extracts of sugar beet and henna. The results agreed with Cheng et al. (2014) who proclaimed the ability of $80 \%$ alcohol extraction of red beet and China rose to stain the outer mammilated surface of Ascaris lumbericoides, which outer surface was stained brown and dark brown in distilled water extraction of red beet and China rose respectively. Staining of aqueous extract of sugar beet, henna produced characteristics of oral/ ventral sucker, cirrus sac and intestinal ceca's branches of $F$. gigantica very similar to aqueous extract of China rose and carmine stain. Daryani and Meigouni (2010) used alizarin, henna and curcuma to stain $F$. hepatica, alizarin was more efficient than henna and curcuma in staining, especially suckers, branched intestine, vitelline glands, vitelline duct, ootype and body spines. However, staining of aqueous extract of sugar beet and henna produced characteristics of vitelline ducts and vitelline glands almost similar to aqueous extract of China rose and carmine stain but little better quality was seen in samples stained by them. The results agreed with Maraghi and Sami (2001) who used juice of a berry, boiled beet for staining of parasites and found that dyes were almost like carmine.

\section{Conclusion}

Since natural herbal dyes are cheap, safe for staining of Fasciola gignatica, and the results evidenced that extract of red beet, China rose and henna showed higher scores and better quality than the conventional dye in staining procedure in the taxonomic study of helminthes parasite. Red beet, henna and China rose can be alternatives to industrial 
dyes such as carmine.

\section{References}

Afshar, V, 2001: The process and methods of dyeing fibers with natural dyes. Art University Press, 3:1.

Al-Amura, MF, Hassen, ZA, Al-Mhanawi, B H, 2012: Staining technique for helminth parasites by use red beet (Beta vulgaris $L$.) extract. Bas. J. Vet. Res., 9,1: 283-92.

Attokaran, M, 2012: Natural Food Flavors and Colorants. Wiley-Blackwell, Washington, DC.

Avwioro, 0. 2002: Histochemistry and Tissue Pathology. Claverianum Press.

Bhuyan, R, Saikia, CN, 2005: Isolation of color components from native dye bearing herbals in northeastern India. Bioresour. Technol. 96, 3: 363-72.

Boris, N, Zbigniew, P, Aneta, P, Pawel, S, Wayne, et al, 2011: Betalainic and nutritional profiles of pigment- Enriched red beet root. Food Chem. 127:42-5

Cheng, CW, Saad, SM, Abdullah, R, 2014: Alternative staining using extracts of hibiscus (Hibiscus rosasinensis L.) and red beet (Beta vulgaris $L$.) in diagnosing ova of intestinal nematodes (Trichuris trichiura and Ascaris lumbricoides). Eur. J. Biotechnol. Biosci. 1, 5:14-8.

Chukwu, OO, Odu, CE, Chukwu, DI, Hafiz, N, Chidozie, VN, et al, 2011: Application of extracts of henna (Lawsonia inamis) leaves as a counter stain. Afr. J. Microbiol. Res. 5, 21:3351-6.

Daryani, AM, Meigouni, M, 2010: Staining of Fasciola hepatica by natural herbal dyes. Comparat. Clin. Pathol. 20, 4:305-8.

Eom, S, Shin, D, Yoon, K, 2001: Improving the dye ability of natural colourants on cotton by cationization. Ind. J. Fib. Text. Res. 26, 4:425-31.

Ghavami, MB, Rahimi, P, Haniloo, A, Mosavinasab SN, 2009: Genotypic and phenotypic analysis of Fasciola isolates. Iran J. Parasitol. 4, 3 : 61-70.

Kumar, N., Mehul, J, Das, B, Solanki, JB, 2015: Staining of Platyhelminthes by herbal dyes: An eco-friendly technique for the taxonomist. Vet. Wld. 8, 11:1321-25.
Kumar, A, Singh, A, 2002: Review on Hibiscus rosa sinensis. Int. J. Pharm. Biomed. Sci. 3, 2: 534-38.

Maraghi, S, Sami, M, 2001: Staining of helminthes using herbal dyes. In: Proc. $3^{\text {rd }}$ Nat. Cong. Med. Parasitol. Sari, Iran. 282

Marhaba, Z, Haniloo, A, 2018: Staining of parasitic helminths by extracts of Allium cepa, Juglans regia, and Rubia tinctorum: An approach to herbal dyes. Iran. J. Parasitol. 13, 2:293-300

Muller, R, 2002: Worms and Human Disease. $2^{\text {nd }}$ ed. London: CABI Publishing.

Ratna, D, Padhi, BS, 2012: Pollution due to synthetic dyes toxicity and carcinogenicity studies and remediation. Int. J. Environ. Sci. 3, 3:94055.

Roberts, LS, Janovy, JJ, 2005: Foundation of Parasitology. $5^{\text {th }}$ ed. Wm. C. Brown Publisher: McGraw Hill Comp. Inc.

Roy, K, Gullapalli, S, Chaudhuri UR, Chakraborty, R, 2004: The use of a natural colorant based on betalain in the manufacture of sweet products in India. International J. Food Sci. Technol. 39:1087-91

Saati, EA, Simon, BW, Yunianta, I, Aulanniam, A, 2011: Isolation of red rose anthocyanin pigment and its application to inhibit lipid oxidation in yoghurt. J. Agric. Sci. Technol. 1192-95.

Semwal, RB, Kumar, DS, Combrinck, S, Cartwright, C, Viljoena, A, 2014: Lawsonia inermis L. (henna): Ethnobotanical, phytochemical and pharmacological aspects. J. Ethno-pharmacol. 155, 1:80-103

Sidram, NA, Sachin, GL, Kalyane, NV, 2011: Study on anti-solar activity of ehanolic extract of flower of Hibiscus rosasinensis Linn. Res. J. Pharm. Technol. 4, 3:472-3.

Suebkhampet, A, Naimon, N, 2014: Using dye plant extract for histological staining. J. Mahanakhon Vet. Med. 9, 1:63-78.

Yoshikazu, T, Bruglier, F, Chandler, S, 2009: Recent progress of flower color modificat-ion by biotechnology. Int. J. Mol. Sci. 10: 5350-69.

Zeibig, EA, 2013: Clinical Parasitology: A Practical Approach. Elsevier Saunders.

\section{Explanation of figures}

Fig. 1: Adult F. gigantica stained A: by aqueous extract of China rose, B: by aqueous extract of sugar beet, C: by aqueous extract of henna, D: by acid carmine stain $\mathrm{X} 4$

Fig.2: oral sucker, pharynx, oesophagus of $F$. gigantica stained A: by aqueous extract of China rose, B: by aqueous extract of sugar beet, C: by aqueous extract of henna, D: by acid carmine stain X10.

Fig. 3: Ventral sucker of $F$. gigantica stained A by aqueous extract of China rose, B: by aqueous extract of sugar beet, C: by aqueous extract of henna, D: by acid carmine stain X10.

Fig. 4: Ovary of $F$. gigantica stained A: by aqueous extract of China rose, B: by aqueous extract of sugar beet, C: by aqueous extract of henna, D: by acid carmine stainX10 
Fig. 5: Testes of F. gigantica stained A:by aqueous extract of China rose, B: by aqueous extract of sugar beet, C: by aqueous extract of henna, D: by acid carmine stainX10.

Fig. 6: Longitudinal exeretory canal/pore of $F$. gigantica stained A: by aqueous extract of China rose, B: by aqueous extract of sugar beet, C: by aqueous extract of henna, D: by acid carmine stain X10.

Fig.7: Vitelline glands and vitelline ducts of F. gigantica stained A: by aqueous extract of China rose, B: by aqueous extract of sugar beet, C: by aqueous extract of henna, D: by acid carmine stain X10.

Fig. 8: Uterus of $F$. gigantica stained A: by aqueous extract of China rose, B: by aqueous extract of sugar beet, C: by aqueous extract of henna, D: by acid carmine stain X10.

Fig. 9: Ootype / mehli's gland and yolk reservoir of $F$. gigantica stained A: by aqueous extract of China rose, B: by aqueous extract of sugar beet, C: by aqueous extract of henna, D: by acid carmine stain X10.

Fig.10: Spines of $F$. gigantica stained A: by aqueous extract of China rose, B: by aqueous extract of sugar beet, C: by aqueous extract of henna, D: by acid carmine stain X40
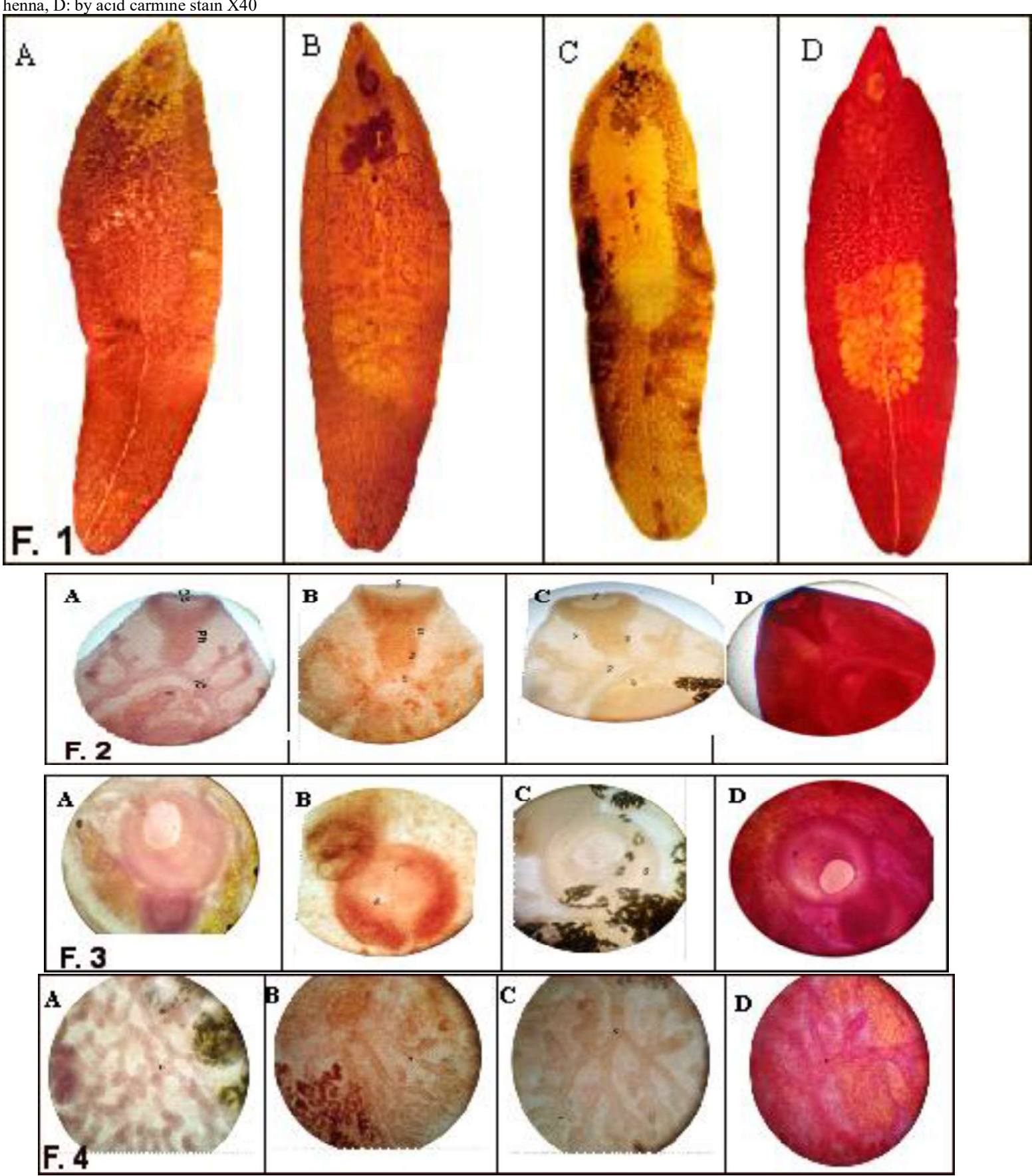

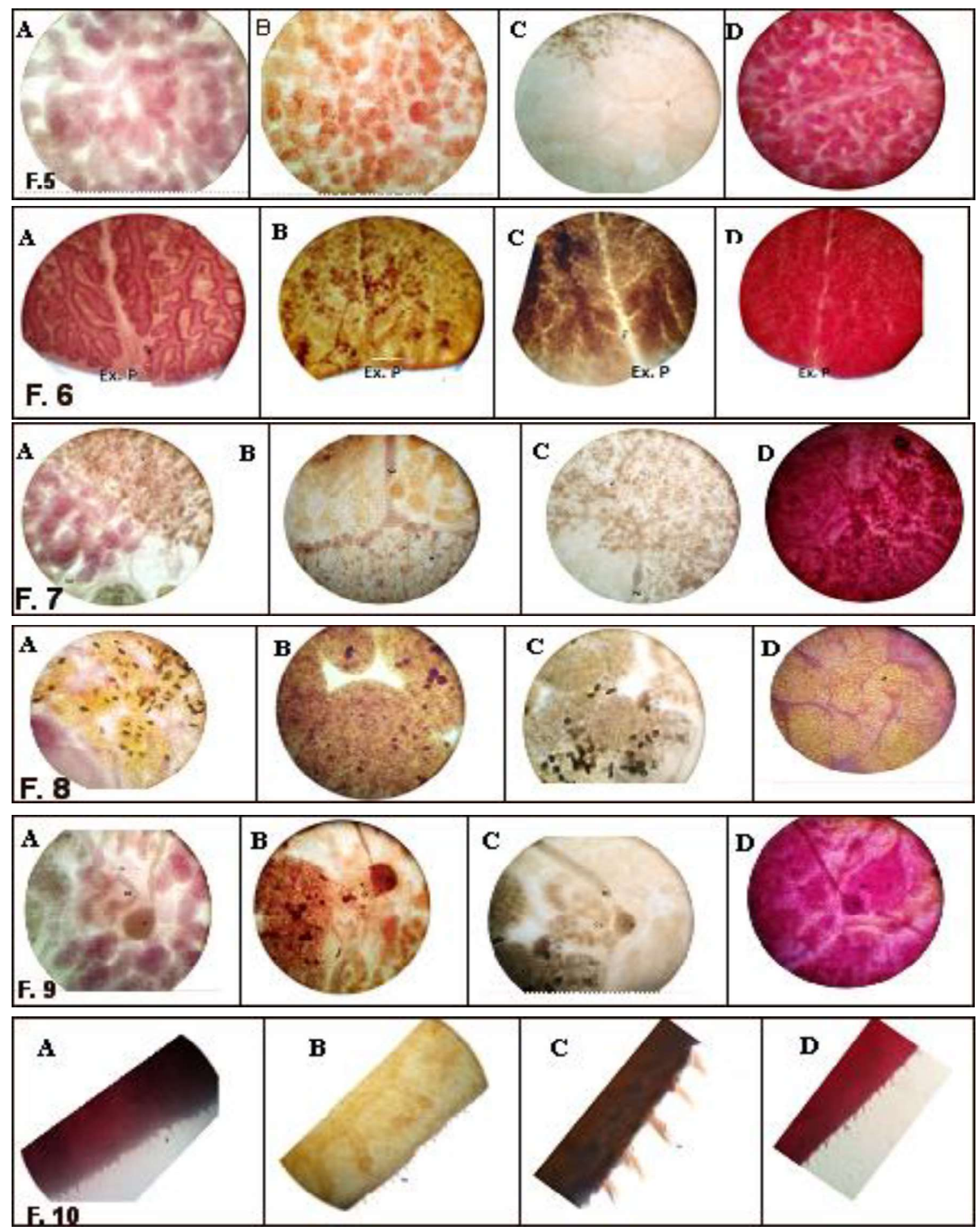